Proc. Estonian Acad. Sci. Eng., 2001, 7, 3, 212-221

\title{
SEASONAL WIND STABILITY ON THE WEST ESTONIAN COAST
}

\author{
Teolan TOMSON and Maire HANSEN \\ Estonian Energy Research Institute, Paldiski mnt. 1, 10137 Tallinn, Estonia; teolan@anet.ee \\ Received 31 January 2001, in revised form 4 May 2001

\begin{abstract}
Two characteristic seasons can be distinguished in the winds prevailing in Estonia: winter and summer. Summer is characterized by a periodical daily wind component at the coast as well as on the mainland. Filtering it out from the time series, the rest of the data can be considered as the random component of the wind velocity. The length of its correlation interval, about $10 \mathrm{~h}$, determines the stability of the wind velocity. It is shown that data obtained at the height of 10-12 m with a 3-h step is sufficient to establish the correlation interval. The average value of the wind velocity and its correlation interval depend more strongly on the season than on the location.
\end{abstract}

Key words: wind velocity, random component, correlation interval.

\section{INTRODUCTION}

For implementation of the wind energy, not only the mean value of the wind velocity but also its stability is of interest. By "stability" in this paper we mean the nearly constant short-time (hour, day) mean value of the wind velocity.

Wind velocity as a function of time is a superposition of periodic, quasiperiodic and random components. At least two periodic components can be distinguished: daily and yearly. There may be also other components with a longer period, for example those related to the 11-year cycle of solar activity, etc. The yearly periodicity is related to the relatively stable big cyclone evolving over the North Atlantic Ocean in winter and an anticyclone in Siberia which both develop subcyclones on their way over the British Isles, South Scandinavia, the Baltic Sea and North-West Russia to the Arctic [ $\left.{ }^{1}\right]$. In case when the subcyclones have developed within a certain period of time and their route is permanent, the wind velocity in Estonia starts to change quasi-periodically, mostly with a 3-4 day period $\left[{ }^{2}\right]$. The daily periodicity results from the unequal warming up of land and sea during a day. This phenomenon is observed only in summer from May till September $\left[{ }^{3}\right]$. 


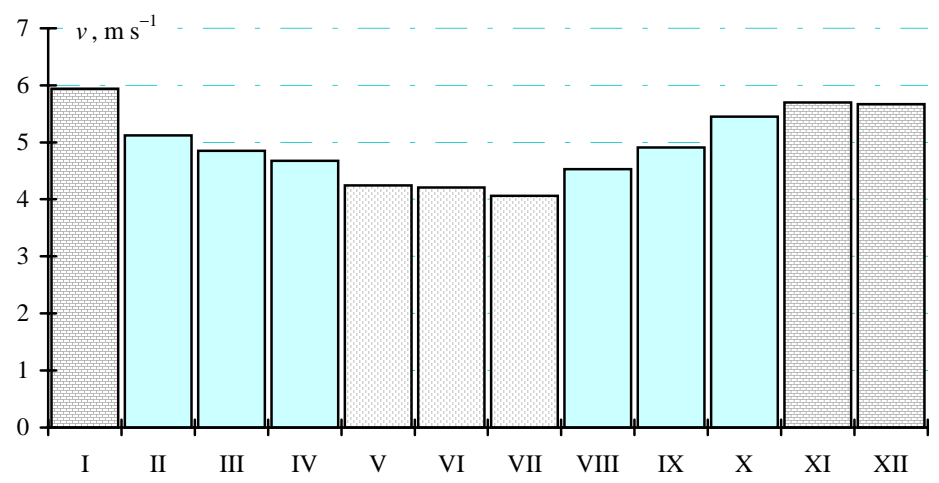

Fig. 1. Monthly average wind velocities on the Estonian western coast

Figure 1 shows seasonal character of the wind velocity in West Estonia. Average wind velocities were measured at meteorological stations at Harku, Kuressaare, Pakri and Vilsandi in 1983-1993. Average wind velocities in winter (from November till January) are 38\% higher than those in summer (from May till July). However, average wind velocity variation during both characteristic seasons is not significant. In the intermediate seasons, spring and autumn, the average variation of velocities is characterized by a decreasing or increasing trend.

The objective of this study is to evaluate how rapidly the average wind velocity $v$ varies (in statistical meaning). The variation of the wind velocity (or wind power) must be taken into account by considering application of wind energy in the Estonian power system. We also want to find out whether this variation is uniform all over the Estonian territory and, particularly, over the West Estonian coast.

The correlation interval of the random wind component serves as the basis for this analysis.

\section{METHOD}

Existence of the random component suggests application of the correlation analysis. For this purpose we shall use synchronous measurements (6546 observations) made at the automatic monitoring stations of Harilaid and Kihnu from November 6 to December 31, 1999.

\section{Required sampling interval}

Following the Kotelnikov theorem (the Nyquist criterion), any signal can be reproduced if the condition $f>2 F$ is observed. Here $f$ is sampling frequency and $F$ is the highest frequency in the spectrum of the measured signal. For detecting 


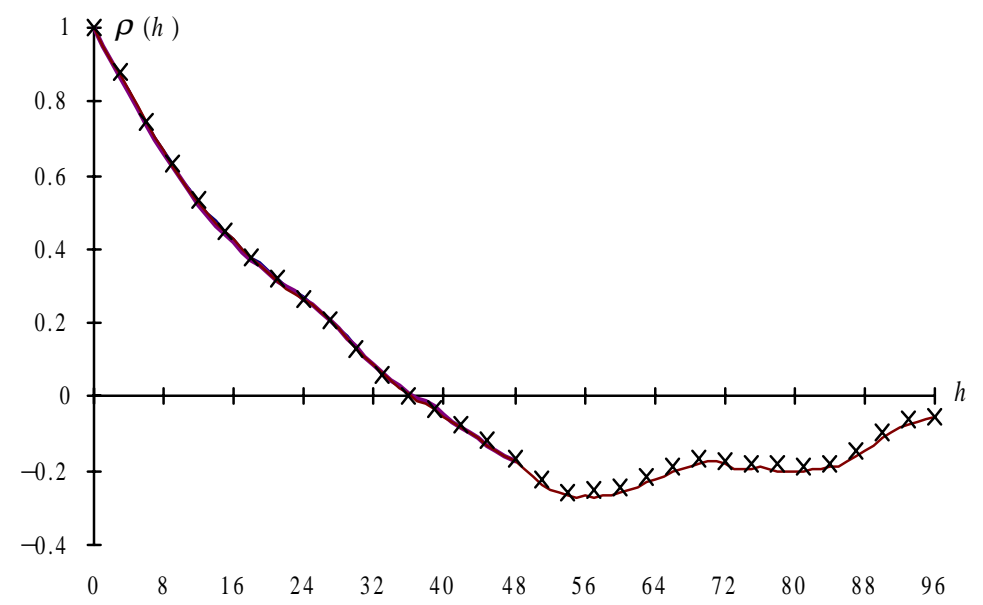

Fig. 2. Autocorrelation function $\rho(h)$ of the wind velocity; observation intervals $\Delta t:-10 \mathrm{~min}$, $1 \mathrm{~h} ;-30 \mathrm{~min} ; \times 3 \mathrm{~h}$.

the daily periodic component, the minimum required sampling interval is $12 \mathrm{~h}$. Since the random component of the wind was not known beforehand, the wind velocity was measured with $10 \mathrm{~min}$ intervals both at Harilaid and Kihnu. The autocorrelation functions (ACF) of the wind velocity were calculated from different time series with different sampling intervals (Fig. 2). Similar results were obtained for ACF at Harilaid using measurements at the height of $20 \mathrm{~m}$. Coincidence of the curves for different sampling intervals proves that the 3-h interval is sufficient and due to this, database of the hydro- and meteorology service can be used for the analysis of the random component of the wind velocity. The expected correlation interval for the random component of the wind velocity is in the order of $10 \mathrm{~h}$.

\section{Necessary measurement height}

From the point of view of power engineering, we are interested in wind behaviour at the height of $30-60 \mathrm{~m}$. However, up to now the majority of measurements have been made at the height of 10-12 m. Therefore wind velocity measurements were carried out at bigger heights both at Kihnu and Harilaid (Fig. 3). Since the ACFs of the wind velocity for various heights are quite close to each other (the correlation interval varies less than 5\% at different heights), the random component of wind can be analysed using measurement data for the height of $10 \mathrm{~m}$. However, the mean values $\mu(v)$ and variances $\sigma^{2}(v)$ of the wind velocity are different at different heights (Table 1 ). 


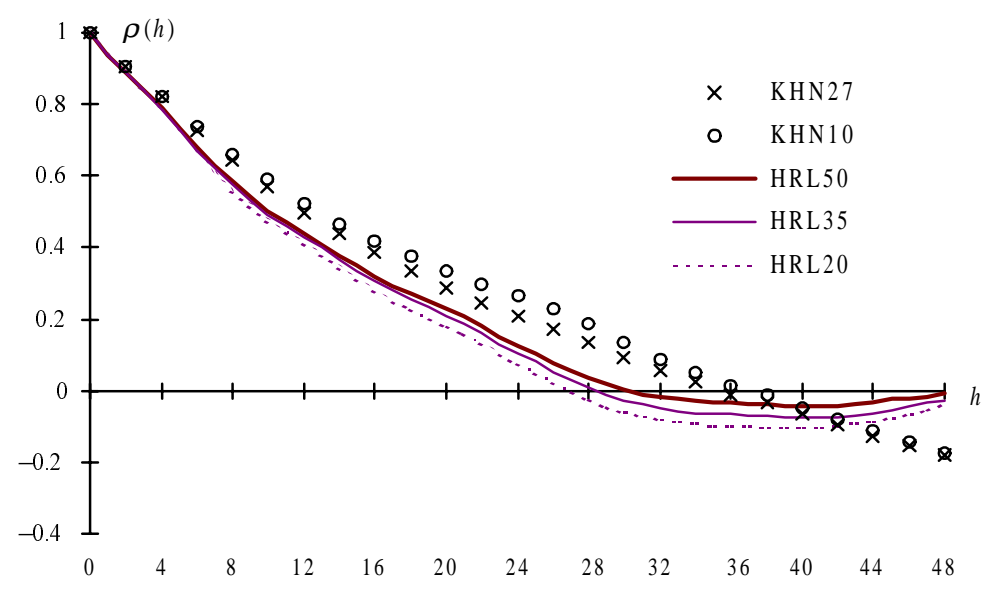

Fig. 3. Dependence of the autocorrelation function on the height of the wind velocity measurement at Kihnu (KHN) and Harilaid (HRL).

Table 1. The mean values $\mu(v)$ and variances $\sigma^{2}(v)$ of the wind velocity $v$ as functions of the measurement height $H$

\begin{tabular}{c|ccc}
\hline Site & $H, \mathrm{~m}$ & $\mu_{\epsilon}(v), \mathrm{m} \mathrm{s}^{-1}$ & $\sigma_{\epsilon}^{2}(v), \mathrm{m} \mathrm{s}^{-2}$ \\
\hline Kihnu & 27 & 10.14 & 17.93 \\
& 10 & 8.07 & 15.16 \\
Harilaid & 50 & 10.76 & 17.08 \\
& 35 & 10.15 & 16.21 \\
& 20 & 9.56 & 13.77
\end{tabular}

\section{Required measurement duration}

The longer time series we use, the smoother the calculated ACF will be and the more general the result. On the other hand, the time series must not exceed the duration of the considered characteristic season since otherwise we loose the features, characteristic to this season. From the condition of smoothness of the ACF, the analysed time series should include at least 300-1000 recordings.

\section{Necessary ACF length}

From the selected range of the time lag and from the available time series follows that the length of the ACF could reach weeks. However, this length has no sense due to the well-known characteristics of the wind velocity (the possible quasi-periodic phenomena) and only some single ACFs will converge in the given lag limits (i.e., will reduce asymptotically to zero). To elucidate the daily periodic component, the ACF length should be at least two to three days (48$72 \mathrm{~h}$ ). When (in winter) there is no daily periodic component present, the delay must be at least from 5 to 10 sampling intervals so that the initial part of the ACF can be approximated with the exponential function. 


\section{Correlation interval}

Correlation interval shows the time lag by which the wind velocity is not statistically correlated with its current value any more. In this case the wellknown criteria $\left[{ }^{4}\right]$ cannot be used due to the above described characteristics of the ACF of the wind velocity. These criteria are mostly based on the reduction of the integral of the ACF to zero. Analysing the wind velocity, such ACFs are exceptional. Therefore below the time constant of the ACF, approximated by an exponential function, is used for the value of the correlation interval. This function is found from the condition that the integral of the error has a minimum during the time when the calculated ACF is reduced to the value of 1/e.

\section{DATA PREPARATION}

The long-term analysis is based on the following data: 1) for winter (9 seasons) and summer ( 9 seasons), measured at Harku in the years 1983-1994 and 2) for winter (11 seasons) and summer ( 9 seasons), measured at Kuressaare in the years 1982-1994.

The short-term analysis is based on the measurement results according to Table 2. This analysis shows the difference of marine sites (small islands and islets) from those on the coast. The measurement sites are shown in Fig. 4.

The linear trend of the wind velocity $\left[{ }^{5}\right]$ was eliminated from all the 3-h interval databases, independent of the location and time. From all summer timeseries the daily periodic component was eliminated using the following method. Throughout the whole daily measuring period 0000-2100 GMT, the average wind velocity at each measuring moment was found and subtracted from the current value of the wind velocity at the respective moment. The rest is considered as the random value of the complex wind velocity. That characterizes instability of the wind and ACF was calculated for this component. Corresponding ACF for the directly measured wind velocity was calculated too

Table 2. The mean values $\mu(v)$ and variances $\sigma^{2}(v)$ of the wind velocity $v$ at different sites

\begin{tabular}{lc|l|c|c}
\hline \multicolumn{1}{c}{ Site } & Abbreviation & \multicolumn{1}{c|}{ Time } & $\mu(v), \mathrm{m} \mathrm{s}^{-1}$ & $\sigma^{2}(v)^{*}, \mathrm{~m} \mathrm{~s}^{-2}$ \\
\hline Harku & HRK & Winter, 1983-1994 & 4.25 & 4.05 \\
& & Summer, 1983-1994 & 3.18 & 1.96 \\
Kuressaare & KRS & Winter, 1982-1994 & 5.52 & 8.28 \\
& & Summer, 1982-1994 & 4.34 & 3.69 \\
Harilaid & HRL & Summer, 1998 & 7.09 & 12.79 \\
Kihnu & KHN & Summer, 1999 & 4.60 & 5.82 \\
Osmussaar & OSM & Aug, 1994 & 6.52 & 12.56 \\
Prangli & PRG & June, 1993 & 5.32 & 7.93 \\
Sorve & SRV & Summer, 1991 & 5.73 & 7.88 \\
Vilsandi & VLS & Summer, 1994 & 4.99 & 7.28
\end{tabular}

* Variance of the random component. 


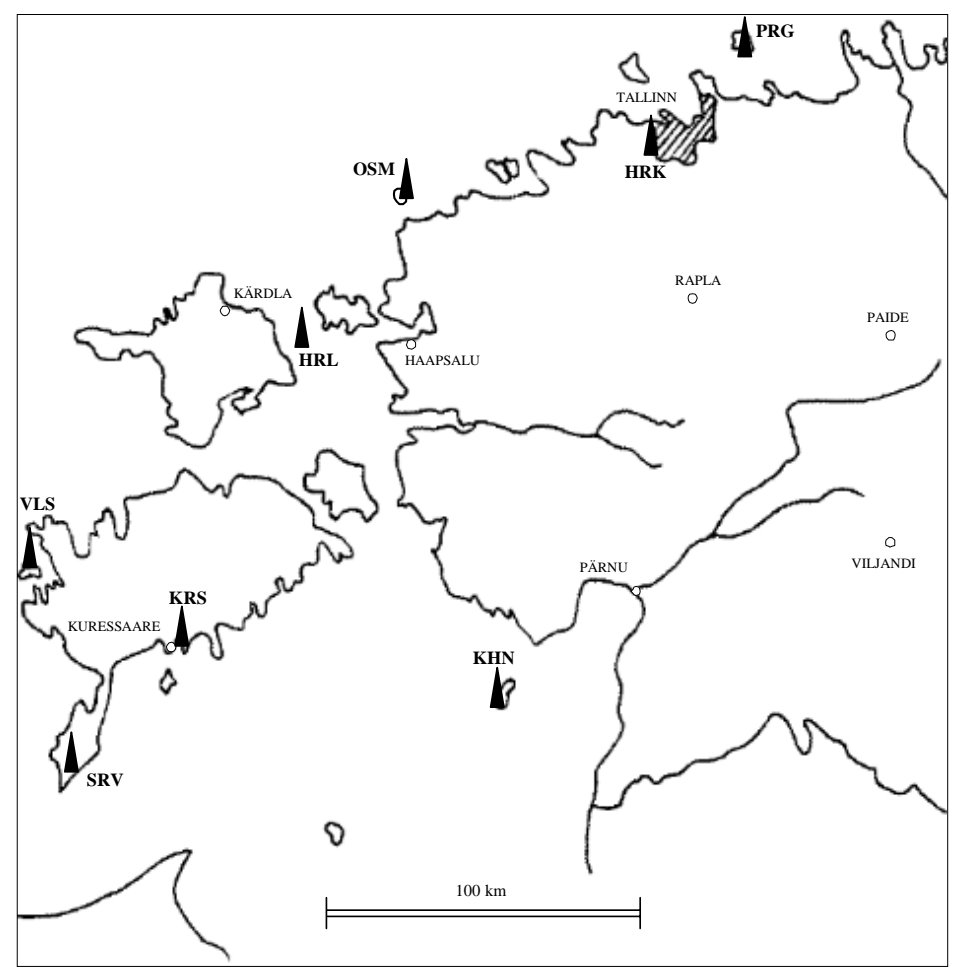

Fig. 4. Measurement sites.

and given on diagrams for comparison in order to show the impact of the periodic component. For long-term analysis, the average ACF is given along with the ACF minimum and maximum values valid for each lag: the ACFs for different years are dispersed to some extent and the sequence of the extreme values makes an envelope of a family of ACFs. For relating the ACF with the actual values of wind velocity, the mean value $\mu(v)$ and variance $\sigma^{2}(v)$ of the wind velocity can be used (Table 2).

The daily average wind velocity diagram in Fig. 5 illustrates the periodic wind component at Kuressaare. This diagram is similar to those obtained elsewhere at the coast. The maximum of the wind velocity coincides with the daily maximum temperature of the ambient air (at 1400 GMT). 


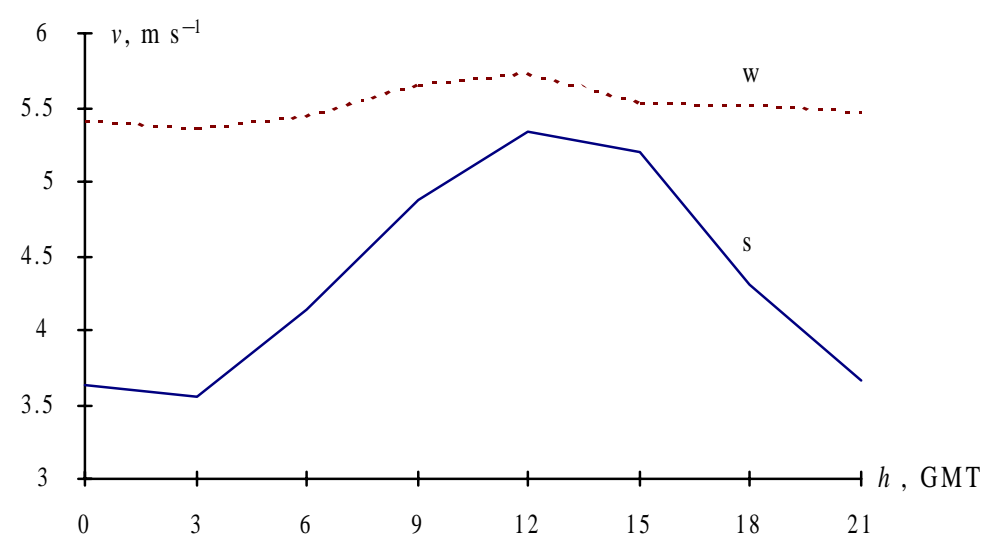

Fig. 5. Average wind velocity variation during a day at Kuressaare in summer (s) and winter (w).

\section{RESULTS}

Wind character is different at the marine and coastal sites. Characteristic feature of the marine sites (islets and small islands) is absence of the daily periodic wind component in summer (Fig. 6). An evidence for this is that the periodic ACF "tail" is absent. Also, ACF based on raw data and that found from the filtered databases (for the periodic component) coincide that proves the same.

$\mathrm{ACF}$ calculated from raw data for summer at the coastal sites (incl. the coasts of big islands) has a distinct periodic "tail". Figure 7 shows it for Harku. In winter such a phenomenon is not observed (Fig. 8). ACF for wind velocity at Kuressaare has the same features. Let us mention that due to yearly fluctuations,

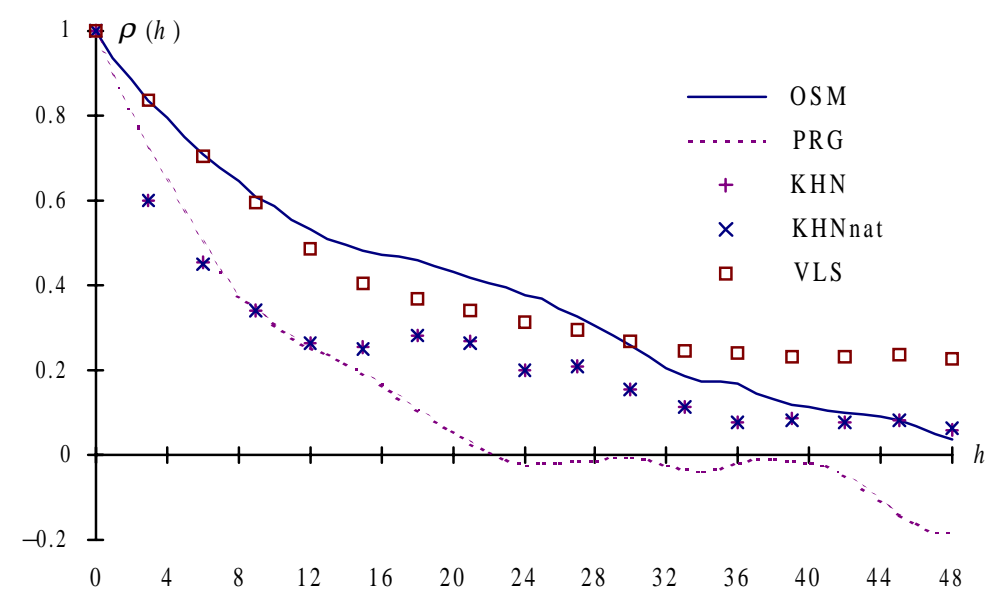

Fig. 6. Autocorrelation functions at the marine sites in summer; KHNnat - unfiltered data. 


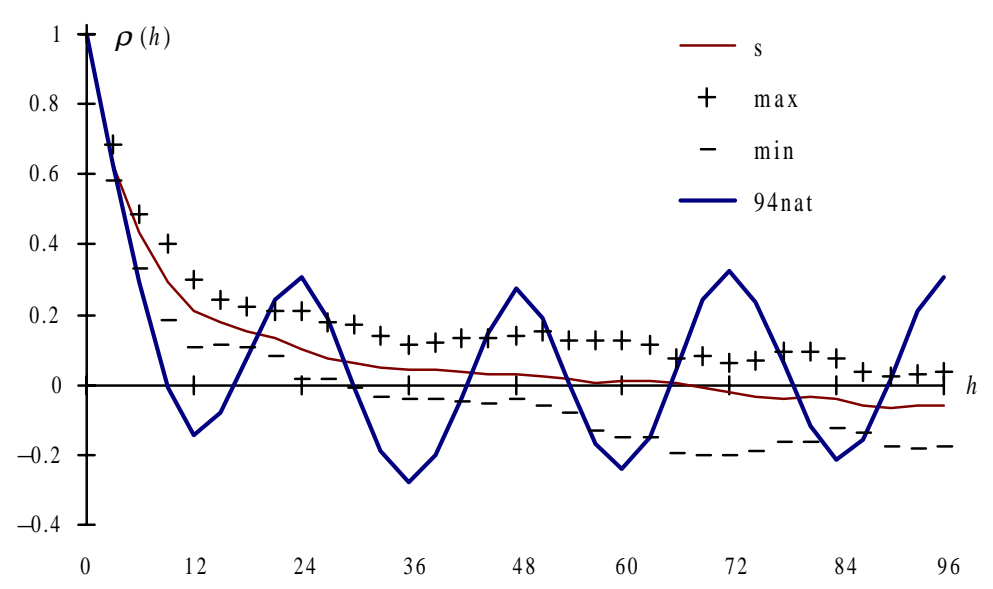

Fig. 7. Autocorrelation function at Harku in summer; s - average for a number of years, 94nat unfiltered data for 1994.

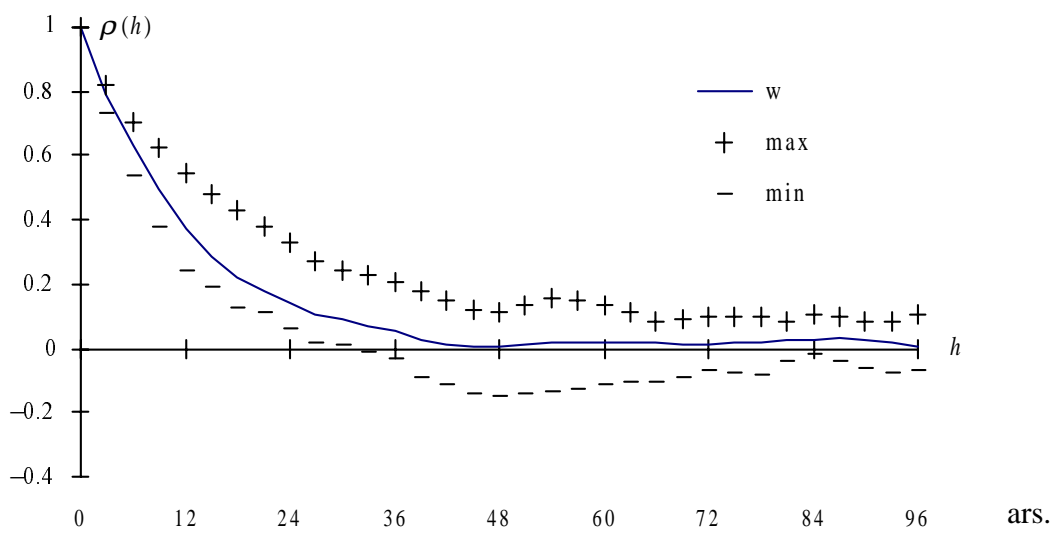

Table 3. The mean values $\mu(v)$ and correlation interval $\tau$ of the wind velocity $v$ as functions of the season and location

\begin{tabular}{lcr}
\hline \multicolumn{1}{c|}{ Site } & $\mu(v), \mathrm{m} \mathrm{s}^{-1}$ & $\tau, \mathrm{h}$ \\
\hline KRS(w) & 5.522 & 14.7 \\
KRS(s) & 4.337 & 10.2 \\
HRK(w) & 4.246 & 12.5 \\
HRK(s) & 3.179 & 7.0
\end{tabular}




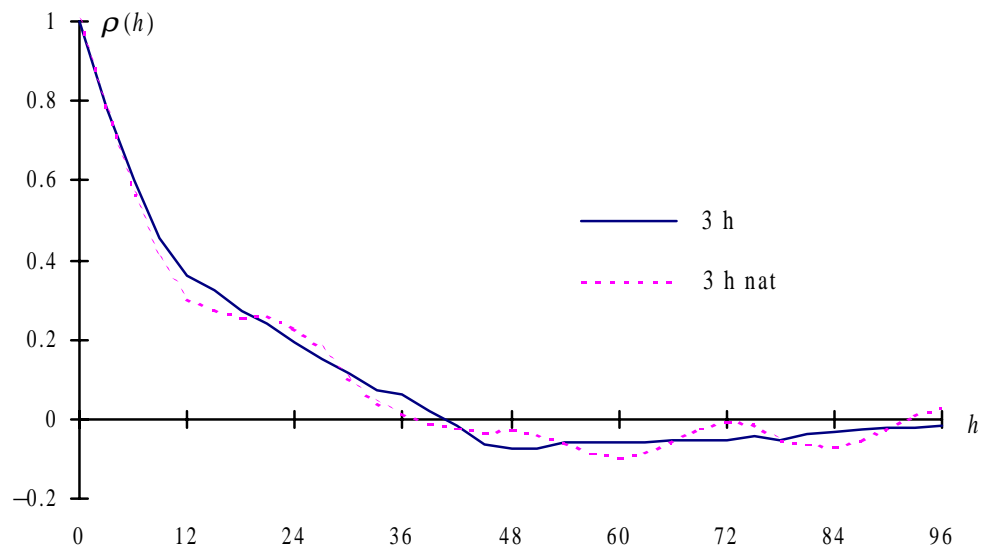

Fig. 9. Autocorrelation function at the Sõrve Peninsula in summer: - calculated from the directly measured wind velocities, ---- calculated from filtered data.

a single ACF is insufficient to draw conclusions. Table 3 shows the correlation intervals $\tau$ and mean wind velocities approximated from the average ACF. We can see that the higher the mean wind velocity, the more stable it is. Longer correlation time is an evidence for this. Significant difference in correlation times for different geographical locations (the distance between Harku and Kuressaare is about $185 \mathrm{~km}$ ) has not been established. Evidently, the random component is uniform due to cyclonic wind while the diameter of cyclones reaches the order of $10^{3} \mathrm{~km}$ and wind field is uniform over large areas.

The ACF of the wind velocity at Sorrve (Fig. 9) is exceptional since a weak periodic component is present (ACF calculated from raw data and that from the filtered data differ slightly). The Sõrve meteorological station is surrounded with water from three sides and the impact of the "continent" remains low. This feature suggest that the periodic component diminishes rapidly on the sea away from the coastline.

\section{CONCLUSIONS}

The following conclusions can be drawn from the performed investigation

1. Measurements made by meteorology services with a 3-h interval at the height of 10-12 $\mathrm{m}$ can be used for investigating the stability of the wind velocity.

2 . The correlation interval of the random component of the wind velocity can be considered as its stability measure.

3 . The stability of the wind velocity is in correlation with the mean value of the latter. Therefore stronger winter wind is more stable. 
4. The stability of the wind at the Estonian western coast at different sites does not vary much.

5. The daily periodic wind component, characteristic to the coast and mainland in summer, is absent on the sea.

6. The exceptional ACF at Sorve may be a sign that the periodic component of the wind diminishes rapidly on the sea off the coastline. This fact should be investigated in more detail since the coastal sea is a perspective site for building offshore wind farms.

\section{REFERENCES}

1. Soomere, T. and Keevallik, S. Anisotropy of moderate and strong winds in the Baltic Proper. Proc. Estonian Acad. Sci. Eng., 2001, 7, 35-49.

2. Tomson, T. and Hansen, M. Wind dynamics in the Moonsund Archipelago. Proc. Estonian Acad. Sci. Eng., 2000, 6, 61-69.

3. Tomson, T. Periodical component of the West Estonian wind. Proc. Estonian Acad. Sci. Eng., $2001,7,50-57$.

4. Romanenko, A. F. and Sergeev, G. A. Problems of the Applied Analysis of Random Processes. Sov. Radio, Moscow, 1968 (in Russian).

5. Bendat, J. S. and Piersol, A. G. Random Data: Analysis and Measurement Procedures. Mir, Moscow, 1974 (in Russian).

\section{LÄÄNE-EESTI TUULE SESOONNE STABIILSUS}

\section{Teolan TOMSON ja Maire HANSEN}

Eestis valitsevatel tuultel on kaks iseloomulikku sesooni: talvine ja suvine. Suvesesooni iseloomustab rannal ja mandril tuule ööpäevane perioodiline komponent, mille väljafiltreerimisel andmebaasist jääb alles tuule juhuslik komponent. Viimase korrelatsiooniintervalli pikkus, ligikaudu 10 tundi, määrab tuule kiiruse stabiilsuse. On näidatud, et korrelatsiooniintervalli määramiseks piisab 3-tunnise intervalliga 10-12 m kõrgusel tehtud mõõtmistest, kusjuures korrelatsiooniintervall (seega ka tuule stabiilsus) on seotud rohkem sesooniga kui asukohaga. 